\title{
O Estado da Arte da Produção Científica em Economia Solidária
}

\section{The State of Art of Scientific Production on Solidarity \\ Economy}

Daniel Calbino Pinheiro

Mestre e Doutor em Administração pela Universidade Federal de Minas Gerais. Professor da Universidade Federal de São João Del-Rei. Brasil, dcalbino@yahoo.com.br

http://lattes.cnpq.br/4784709340714266

Resumo: Com o intuito de trazer aportes para a discussão da gestão na Economia Solidária, o presente trabalho, de natureza teórica empírica, propôs-se a realizar um estudo da arte sobre a produção na área de Administração. Enquanto percurso metodológico, recorreu-se ao uso de palavras-chave e títulos que se associam ao tema, investigando as dissertações e teses, os periódicos do Extrato A1 a C da Capes e os congressos na área de Administração entre 1970 a 2013. Enquanto resultados e contribuições, a presente revisão da literatura apresentou o balanço da produção da temática problematizando seus limites e desafios, bem como ilustrou alguns trabalhos que trazem inovações para a discussão da gestão nas organizações de Economia Solidária.

Palavras-chave: Economia Solidária, Gestão, Balanço da Produção.

Abstract: In order to bring contributions to the discussion of management in the Joint Economy, this theoretical-empirically study proposed to conduct a study of art on the production in the business area. As a methodology, the use of keywords and titles, that are associated with the subject, was made, investigating the dissertations and theses, the periodicals, and the congresses in the Administration area, between the years 1970 to 2013 . Regarding results and contributions, the present review of the literature reports on the issue of production, questioning its limits and challenges and also illustrated some works that bring innovations to the discussion of management in the Joint Economy organizations.

Key-words: Solidarity Economy, Management, Balance of Production.

Texto completo em português: http://www.apgs.ufv.br Full text in Portuguese: http://www.apgs.ufv.br

\section{Introdução}

As décadas de 1970 e 1980 foram marcadas pelo aumento vertiginoso do desemprego na maioria dos países, consequência de uma crise econômica mundial e da reestruturação produtiva. Nessa conjuntura desfavorável aos trabalhadores, floresceram propostas que marcaram os anos de 1990 como reação ao processo de fechamento de postos de trabalho, de exclusão social, da crise de valores e de ideais emancipatórios (Guerreiro et al., 2004; Singer, 2002). Uma delas é chamada de Economia Solidária, que pode ser vista como organizações de cunho econômico e social (na forma de cooperativas, associações, empresas recuperadas, clubes de troca, finanças solidárias, entidades de apoio, redes solidárias) que buscam estabelecer relações solidárias, democráticas e equitativas, movendo-se não apenas para alcançar resultados econômicos, mas também sociais, políticos, culturais (Singer, 2002; Laville, 2003; França Filho, 2008; Gaiger, 2009).

Observa-se, assim, a partir desse período, um aumento significativo das organizações de Economia Solidária em diversas partes do mundo, o que tem também assumido destaque no cenário acadêmico. Um dos pontos presentes na agenda de pesquisa no campo da Administração refere-se aos modos de organização das iniciativas de Economia Solidária, que, por possuírem em tese objetivos distintos dos das organizações tradicionais, exigem outros modos de gestão (Andion, 1998, 2005; Costa, 2003, Moura \& Meira, 2002; Magalhães, et al., 2004; Costa \& Carrion, 2011).

Porém, apesar do avanço das pesquisas na temática, o que se observa ao realizar uma revisão da literatura é que ainda há uma escassez de referenciais teóricos e instrumentais da gestão que reflitam e contribuam para as especificidades das organizações solidárias. Há 15 anos, Andion (1998) ressaltava a necessidade de repensar as técnicas, bem como as subáreas da Administração para o contexto da Economia Solidária. Estudos posteriores de Moura e Meira (2002), Costa (2003), Magalhães et al. (2004), Calbino e Paes de Paula (2013) mapearam o que havia sido produzido sobre as organizações solidárias, constatando uma lacuna na literatura e a urgência de criação de instrumentais condizentes.

No mesmo sentido, França Filho (2008) apontava que a falta de um conhecimento de natureza aplicada sobre a lógica de funcionamento e gestão em Economia Solidária incorre no risco de importar metodologias e ferramentas de gestão oriunda do setor privado-mercantil, cujo efeito é o forte risco de isomorfismo institucional, no sentido de incorporarem a racionalidade do mercado e, assim, não atingirem os objetivos a que se propõem.

Motivados por esses fatores, e com o intuito de trazer aportes para a discussão da gestão na Economia Solidária, o presente trabalho,de natureza teórica empírica, propõe-se a realizar um 
balanço sobre a produção acadêmica na área de Administração.Enquanto percurso metodológico,recorrer-se-á ao uso de palavras-chave e títulos que se associam ao tema para a identificação e seleção dos trabalhos, investigando as dissertações e as teses, os periódicos do Extrato A1 a $C$ da Capes e os congressos categorizadosno Extrato $E 1$ na área de Administração, entre 1970 e 2013.

Como contribuição para a área, propõe-se, com a presente revisão da literatura, apresentar uma análise sobre a produção da temática, problematizando seus limites e desafios, bem como ilustrar alguns trabalhos que trazem inovações para a discussão da gestão nas organizações de Economia Solidária.

\section{Uma breve discussão da gestão na Economia Solidária}

Debater o que se entende por gestão passa por uma diversidade de concepções, o que aponta para a impossibilidade de considerá-la como neutra. Isso é observado quando se comparam as definições que adotam pontos de vista epistemológicos distintos. Enquanto algumas visões de cunho funcionalista defendemque a gestão se trata de um conjunto de procedimentos formais que visam à eficiência econômica (Fayol, 1980; Kotler \& Armstrong, 2012), nas perspectivas críticas as afirmativas se baseiam em relativizar a lógica de eficiência nas organizações (Gaiger, 2009; Calbino \& Paes de Paula, 2014), além de questionar as ideologias implícitas em seus modos de gestão (Tragtenberg, 1971; Motta, 1981; Alvesson \& Willmott, 1992; Faria, 2009).

Ainda que se tentasse adotar um contexto genérico de gestão, tratando-a, por exemplo, como um conjunto de procedimentos constituídos por princípios, teorias, técnicas e/ou subáreas que visam alcançar objetivos, somente ao defini-lo já se apresentaria uma visão de mundo diferente. Desse modo, conforme advogam Andion (2005) e Rutkowski (2008), lógicas diferentes acarretam necessidades distintas, o que leva ao questionamento da propriedade do uso de metodologias e métodos de gestão para contextos organizacionais distintos.

No caso da Economia Solidária que se manifesta por meio de uma pluralidade de atividades voltadas para a geração de trabalho e renda, envolvendo empreendimentos produtivos e de prestação de serviços, esses empreendimentos assumem formas variadas de organização (cooperativas, associações, grupos não formalizados) e apresentam características marcantes que os distinguem da atividade econômica capitalista tradicional.

Em tese, as organizaçõesde Economia Solidária se pautam pela gestão coletiva, propriedade comum dos meios de produção, relações de trabalho não hierarquizadas, que se constituem como um antagonismo às características marcantes da economia mercantil: a separação entre classes de acordo com suas posses, capital ou trabalho (Singer, 2002, 2008; Costa 2003).

No mesmo sentido, enquanto uma organização de Economia Mercantil tem como fim a busca pelo lucro, nos empreendimentos solidários as propostas que a tangenciam geralmente almejam objetivos além dos aspectos econômicos (França Filho, 2008).
Dessa forma, a concepção de um modo de gestão para as organizações de Economia Solidária requer uma racionalidade capaz de considerar o mundo da vida e suas múltiplas interrelações, os quais exigem uma ética própria. Isso implica considerar o caráter multidimensional dos objetivos perseguidos por esses empreendimentos, compreendendo a própria eficiência baseada na primazia do trabalho sobre o capital (Rutkowski, 2008).

Sendo assim, devido ao caráter múltiplo de objetivos que remetem às organizações solidárias, considerar a gestão na Economia Solidária implica ampliar as dimensões da análise, conforme mostra Andion $(1998,2005)$ ao se situar como uma das pioneiras na proposição de referenciais para a gestão na Economia Solidária. A autora apresenta enquanto norte quatro dimensões que comporiam a especificidade da gestão naEconomia Solidária: a social, a econômica, a ecológica e a organizacional e técnica. A dimensão social vai tratar da interação das pessoas dentro doempreendimento; a econômica, da gestão dos recursos financeiros; a ecológica, das relações com o meio ambiente, com a comunidade e com o ambiente institucional; a dimensão organizacional e técnica, dos aspectos referentes ao funcionamento interno das organizações e seusimpactos sobre os indivíduos.

É nessa última dimensão que talvez a Ciência Administrativa possa concentrar a sua maior colaboração, na tentativa de que a gestão contribua efetivamente para a sustentabilidade dentro da Economia Solidária. Obviamente, todas as demais dimensões estão implicadas nos processos de tomada de decisão desses empreendimentos, mas a identificação preponderante da administração é maior com a dimensão organizacional e técnica (Costa \& Carrion, 2011).

Apesar da discussão conceitual iniciada por Andion (2005), o campo da Economia Solidária figura ainda como um desafio intelectual, que impõe ao pesquisador a necessidade de desconstruir e reconstruir o referencial teórico utilizado para tentar aportar inteligibilidade a esse campo. Esse exercício se faz necessário, dado que os aportes teóricos, tanto da Ciência Econômica quanto da área de Administração, têm-se revelado insuficientes, quando não inadequados, para se dar conta da complexidade dessa realidade (França Filho, 2008; Costa \& Carrion, 2011).

\section{Metodologia}

Em termos metodológicos, a presente revisão sobre a gestão no campo da Economia Solidáriarealizou um balanço da produção, considerando as publicações em âmbito nacional e internacional. Enquanto recorte metodológico, recorreu-se apenas à área da Administração, tanto por ser necessário existir uma delimitação quanto por partir da hipótese que a discussão da gestão na Economia Solidária tende a se concentrar mais nas áreas vinculadas as Ciências Administrativasi.

Ressalta-se também que, com o intuito de abarcar o maior número possível de concepções que se aproximam ou tentar criar 
fronteiras com o tema Economia Solidária, foram selecionados trabalhos que faziam referência a etimologias similares. Porém, não foram enquadradas as organizações coletivistas de caráter patronal, além das temáticas referentes às organizações que não faziam menção a formatos coletivos de gestão e/ou trabalho.

Enquanto escopo de análise, foram investigados os trabalhos de dissertações e teses do banco de dados da Capes, periódicos nacionais e internacionais classificados nas categorias A1, A2, B1, B2, B3, B4, B5 e C das áreas de Administração (triênio 2011, 2012, 2013) e artigos dos encontros da área de Administração, Ciências Contábeis e Turismo classificados no Extrato E1 da Capes.

Quanto às dissertações e teses nacionais investigadas, recorreu-se à pesquisa acessando o portal do banco de dados da Capes, que disponibilizava trabalhos do período de 1987 a 2013 ii. Já no que se refere à produção internacional de dissertações e teses, recorreu-se a plataformas como Web of Science, Dialnet, Cybertesis; DART-Europe e-theses Portal e Theses Canada.A investigação nas plataformas ocorreu pelo uso de palavras-chave nos buscadores, utilizando os termos: solidary economy, solidarity economy, social economy, self-management; collective organizations; cooperatives, popular cooperatives, Economia Solidária; autogestión, economia social e organizaciones colectivas.

Quanto aos periódicos nacionais e internacionais, foram revisadas as revistas desde suas primeiras ediçõesiii até o ano de base de 2013, cuja investigação se realizou pela seleção prévia dos artigos baseados nos títulos e resumos que faziam menção à temática e que estavam disponíveis online no site de cada revista.

No que se refere à investigação dos artigos nos anais de congressos, foram mapeados os seguintes eventos com suas edições: EnANPAD (1980 a 2013), 3E (2003, 2005, 2007, 2009, 2012), ENAPG $(2004,2005,2008,2010,2012)$, EMA (2004, 2006, 2008, 2010, 2012), SGIT (2006, 2008, 2010, 2012), ENADI (2007, 2009, 2011, 2013), ENGPr (2007, 2009. 2011, 2013), ENAPQ (2007, 2009, 2011, 2013), ANPTUR (2005, 2007, 2008, 2009, 2010, 2011, 2012, 2013), ANPCONT (2007, 2008, 2009, 2010, 2011, 2012, 2013), ENE (2001, 2003, 2004, 2005, 2006, 2007, 2008, 2009, 2010), SIMPOI (2005 a 2013), CCC-USP (2004 a 2013), CBC (1995 a 2013), CIPL (1999, 2003, 2006, 2009, 2012) A investigação ocorreu com a análise prévia do título e resumo dos trabalhos.

Por fim, enquanto eixos centrais de análise, propôs-se mapear quatro questões norteadoras, a saber: a) quais as visões presentes nos trabalhos sobre o discurso da neutralidade da gestão; b) quais os instrumentos de gestão que os autores propuseram para o contexto da Economia Solidária; c) qual a natureza dos trabalhos e objeto de estudo utilizados para tratar da gestão na Economia Solidária; d) quais dimensões da gestão referentes às bases ontológicas, epistemológicas, princípios, técnicas e áreas funcionais do saber administrativo foram abordadas. Além dessas categorias de análise, após a ilustração do mapeamento geral da produção, buscou-se apresentar algumas das contribuições presentes na literatura em termos de trabalhos que trouxeram ressignificações para se pensar a gestão ${ }^{v}$ no campo da Economia Solidária.

\section{Resultados}

Feitas as considerações sobre os processos metodológicos, os resultados da pesquisa apontam para a presença de um total de 176 trabalhosno período de 1970 a 2013, que tratam da gestão na Economia Solidária na área de Administração. As dissertações e teses nacionais é onde se concentra o maior número, com 56 trabalhos ( $31,8 \%$ da produção), seguidos pelos congressos nacionais, com 55 trabalhos (31,3\% da produção). Em terceiro lugar vêm periódicos, dissertações e teses internacionais, com 38 trabalhos $(21,6 \%$ da produção) e por último os periódicos nacionais, com 27 trabalhos (15,3\% da produção) (Tabela 1).

Tabela 1

Relação dos títulos e números de trabalhos na Administração

\begin{tabular}{|l|r|c|}
\hline Títulos & \multicolumn{1}{|c|}{$\begin{array}{c}\text { Número de } \\
\text { trabalhos }\end{array}$} & $\%$ \\
\hline Dissertações e teses nacionais & 56 & 31,8 \\
\hline Congressos nacionais & 55 & 31,3 \\
\hline $\begin{array}{l}\text { Periódicos, dissertações e teses } \\
\text { internacionais }\end{array}$ & 38 & 21,6 \\
\hline Periódicos nacionais & 27 & 15,3 \\
\hline TOTAL & $\mathbf{1 7 6}$ & $\mathbf{1 0 0}$ \\
\hline
\end{tabular}

Fonte: criada pelo autor

O que chamou a atenção durante a investigação é que a presença de trabalhos nos periódicos internacionais, principalmente dos níveis $\mathrm{A} 1, \mathrm{~A} 2$ e $\mathrm{B} 1$, foi praticamente nula, indicando que o tema não ocupa espaço nos principais periódicos da área qualificados pela Capes. No mesmo sentido, periódicos como o Academy of management, Organization, Organization Studies, Journal of Development Studies, que, em tese, apresentam linhas editoriais críticas para o campo das organizações, não possuíam trabalhos que abordassem a gestão nas organizações solidárias. Tal fato parece se repetir também nas dissertações e teses internacionais de origem Anglo-Saxônica, visto que a produção se concentrou principalmente em autores de origem latino-americanavi.

Do mesmo modo, movimentos de pesquisadores como o Labor ProcessTheorye o Critical Management Studies, que apresentam um perfil crítico nos estudos organizacionais e são destaques no volume de produção em periódicos de renome da área, não destinaram espaço para a análise das organizações coletivistas de trabalho. Esse ponto parece uma lacuna teórica, conforme indicamtambém Paes de Paula et al. (2009) ao analisar esses movimentos, pois, apesar das contribuições na desconstrução da visão tradicional da gestão, não avançaram em termos de proposições gerenciais alternativas.

Vale ressaltar novamente que a pesquisa não se limitou ao diagnóstico apenas do termo Economia Solidária, mas a temas como economia social e autogestão (originados da Europa). Desse modo, a ausência de trabalhos não foi só um fator marcante, mas a própria expressão autogestão, quando presente nos trabalhos, vinculava-se mais a conceitos de grupos polivalentes em empresas privadas e técnicas do modelo japonês 
de gestão do que à etimologia destinada a contrapor os modos heterogestionários de organização do trabalho.

Feita uma breve caracterização da distribuição das produções, outro ponto que se buscou investigar na revisão da literatura foi a concepção presente nos trabalhos sobre 0 discurso da neutralidade da gestão. Sustenta-se que essa questão é chave para mapear como se situa a discussão na área, visto que a não compreensão do caráter ideológico da gestão, conforme aponta França Filho (2008), tende a replicar os mesmos instrumentais de gestão tradicionais para o contexto solidário. Desse modo, as respostas foram categorizadas em: (1) trabalhos que compreendem que a gestão é ideológica e necessita ser ressignificada; (2) trabalhos que compreendem a gestão apenas como neutra e replicada para qualquer contexto organizacional; e (3) trabalhos que não se posicionam ou em que não foi possível se aproximar de um dos pontos acima.

Ressalta-se ainda que, antes de investigar a questão na literatura, tinha-se por hipótese inicial que a concepção dos trabalhos sobre a gestão na Economia Solidária tenderia em sua maioria para discursos de neutralidade da gestão, visto que a área da Administração, de um modo geral, ainda é dominada pela concepção do paradigma funcionalista (Andion, 1998; Dalmoroet al., 2007), o que poderia repercutir inclusive nos estudos sobre a Economia Solidária.

No entanto, os resultados apontaram o contrário, pois a maioria dos autores brasileiros e internacionais - 65,5\% dos autores nos congressos nacionais, $71,1 \%$ dos autores nos periódicos nacionais e $77,8 \%$ dos autores nas dissertações e teses- deram indícios de compreender a concepção da gestão como uma construção política. Por outro lado, ainda que grande parte dos autores na literatura internacional considere a gestão como ideológica (48,2\% dos trabalhos), o número de autores que também replicam uma visão funcionalista sobre o tema chegou a 46,4\% dos trabalhos (Tabela 2).

Ressalta-se também que, dentro da literatura internacional, observou-se na investigação que são nos trabalhos de origem latino-americana que há maior preocupação com uma gestão que contraponha a lógica funcionalista, visto que na maioria dos trabalhos vinculados à literatura europeia e anglo-saxã, tendeu-se a replicar a visão mais pautada pela neutralidade da gestão.

Tabela 2

Concepção ideológica da gestão nos congressos e periódicos nacionais

\begin{tabular}{|c|c|c|c|c|c|c|c|c|}
\hline $\begin{array}{l}\text { Concepções } \\
\text { sobre a gestão }\end{array}$ & $\begin{array}{c}\text { Congressos } \\
\text { nacionais }\end{array}$ & $\%$ & $\begin{array}{l}\text { Periódicos } \\
\text { nacionais }\end{array}$ & $\%$ & $\begin{array}{l}\text { Dissertações-teses } \\
\text { nacionais }\end{array}$ & $\%$ & $\begin{array}{l}\text { Literatura } \\
\text { internacional }\end{array}$ & $\%$ \\
\hline $\begin{array}{l}\text { Compreende que a } \\
\text { gestão é ideológica }\end{array}$ & 36 & 65,5 & 27 & 71,1 & 21 & 77,8 & 27 & 48,2 \\
\hline $\begin{array}{lr}\text { Compreende } & \text { a } \\
\text { gestão } & \text { como } \\
\text { neutra } & \\
\end{array}$ & 13 & 23,6 & 8 & 21,1 & 5 & 18,5 & 26 & 46,4 \\
\hline Não identificado & 6 & 10,9 & 3 & 7,8 & 1 & 3,7 & 3 & 5,4 \\
\hline TOTAL & 55 & 100 & 38 & 100 & 27 & 100 & 56 & 100 \\
\hline
\end{tabular}

Fonte: criada pelo autor

No mesmo sentido, buscou-se na revisão da literatura compreender quais bases e referências utilizadas nos trabalhos compreendiam a gestão enquanto ideológica e assimtraziam algum tipo contribuição para repensar a gestãovii. Para isso, com base na categorização de Paes de Paula e Klechen (2007), os trabalhos foram subdivididos entre teóricos, teórico-empíricos e empíricos. Por teóricos entendem-se aqueles que se limitam a conceitos, proposições, construção e reconstrução de teorias e/ou modelos. Os trabalhos teórico-empíricos partem de um quadro de referências teóricas e buscam confirmá-lo ou refutá-lo por meio da análise dos dados. Já os trabalhos empíricos não apresentam um quadro de referências teóricas, relatando apenas as análises de dados e relatos de pesquisa.
Observou-se que a grande maioria dos trabalhos de origem nacional recorreu a estudos de natureza teórica (Tabela 3), baseando-se nos princípios de socialistas utópicos, dos movimentos cooperativistas, bem como nas ideias de autores brasileiros de renome, como Guerreiro Ramos, Maurício Serva e Fernando Tenório, para discutir a gestão.

Porém, o uso de experiências concretas para trazer contribuições foi limitado, apontando apenas para $16,7 \%$ dos trabalhos nos congressos; $14,8 \%$ nos periódicos e $19 \%$ nas dissertações e teses nacionais (Tabela 3). Uma questão limitante que se levanta é que, apesar da relevância de se basear em teorias presentes na literatura, a falta de casos empíricos que tragam aportes para a gestão nas organizações solidárias incorre no risco de não se inovar sobre o tema, reproduzindo os mesmos conceitos teóricos.

Tabela 3

Base de reflexão para repensar a gestão nos congressos e periódicos nacionais

\begin{tabular}{|c|c|c|c|c|c|c|c|c|}
\hline $\begin{array}{lll}\text { Qual a base } & \text { de } \\
\text { reflexão } & & \text { da } \\
\text { gestão? } & & \\
\end{array}$ & $\begin{array}{c}\text { Congressos } \\
\text { nacionais }\end{array}$ & $\%$ & $\begin{array}{l}\text { Periódicos } \\
\text { nacionais }\end{array}$ & $\%$ & $\begin{array}{l}\text { Dissertações-teses } \\
\text { nacionais }\end{array}$ & $\%$ & $\begin{array}{l}\text { Literatura } \\
\text { internacional }\end{array}$ & $\%$ \\
\hline Teórico & 26 & 72,2 & 23 & 85,2 & 16 & 76,2 & 13 & 48,1 \\
\hline Empírico & 6 & 16,7 & 4 & 14,8 & 4 & 19 & 14 & 51,9 \\
\hline Teórico empírico & 4 & 11,1 & 0 & 0 & 1 & 4,8 & 0 & 0 \\
\hline TOTAL & 36 & 100 & 27 & 100 & 21 & & 27 & 100 \\
\hline
\end{tabular}


predominância da abordagem relacionada aos empreendimentos solidários de pequeno porte, constituídos por cooperativas e associações, ocupando entre $33 \%$ e $44 \%$ dos trabalhos nacionais e internacionais, seguido por algumas comunidades locais em menor escala (3,7\% a 22\%), fábricas recuperadas (entre 4,8 a $8 \%$ ) e cidades e países $(2,7 \%$ a $3,8 \%$ ) (Tabela 4$)$. Tais dados parecem refletir uma leitura empírica da realidade brasileira, pois, conforme aponta o último mapeamento da Senaes (2014), de um total de 33.000 empreendimentos solidários mapeados, a grande maioria são de pequeno porte e no formato jurídico de associações.
Outro ponto que chamou a atenção foi o acentuado número de trabalhos que não indicavam qual a unidade de análise a que destinavam o tratamento da gestão $(23,8 \%$ a $44 \%)$ (Tabela 4$)$, o que pode implicar a limitação de abranger propostas de gestão sem considerar os diferentes tamanhos e tipos organizacionais da Economia Solidária. Sustenta-se que são relevantes a contextualização e a delimitação do objeto de análise a que se destina, haja vista que a simples denominação comum pode esconder uma grande diversidade de práticas que merecem ser consideradas no caso da gestão.

Tabela 4

Tipo de organização baseado para repensar a gestão nos congressos e periódicos nacionais

\begin{tabular}{|c|c|c|c|c|c|c|c|c|}
\hline $\begin{array}{l}\text { Qual o tipo de } \\
\text { organização em que } \\
\text { se baseia? }\end{array}$ & $\begin{array}{c}\text { Congressos } \\
\text { nacionais }\end{array}$ & $\%$ & $\begin{array}{l}\text { Periódicos } \\
\text { nacionais }\end{array}$ & $\%$ & $\begin{array}{l}\text { Dissertações-teses } \\
\text { nacionais }\end{array}$ & $\%$ & $\begin{array}{l}\text { Literatura } \\
\text { internacional }\end{array}$ & $\%$ \\
\hline $\begin{array}{l}\text { Cooperativas- } \\
\text { Associações }\end{array}$ & 13 & 36,1 & 12 & 44,4 & 9 & 42,9 & 9 & 33,3 \\
\hline $\begin{array}{l}\text { Empresas } \\
\text { recuperadas }\end{array}$ & 3 & 8,3 & 2 & 7,5 & 1 & 4,8 & 2 & 7,4 \\
\hline Comunidades locais & 4 & 11,1 & 1 & 3,7 & 3 & 14,3 & 6 & 22,2 \\
\hline $\begin{array}{l}\text { Redes-Cadeias } \\
\text { produtivas }\end{array}$ & 2 & 5,6 & 0 & 0 & 0 & 0 & 0 & 0 \\
\hline Países-Cidades & 1 & 2,8 & 0 & 0 & 0 & 0 & 1 & 3,7 \\
\hline $\begin{array}{l}\text { Incubadoras-Bancos } \\
\text { comunitários-ONGs }\end{array}$ & 1 & 2,8 & 0 & 0 & 3 & 14,3 & 0 & 0 \\
\hline Não especifica & 12 & 33,3 & 12 & 44,4 & 5 & 23,8 & 9 & 33,3 \\
\hline TOTAL & 36 & 100 & 27 & 100 & 21 & 100 & 27 & \\
\hline
\end{tabular}

Fonte: criada pelo autor

Por fim, buscou-se compreender quais dimensões da gestão referentes às bases ontológicas ${ }^{\text {viii }}$ e epistemológicas, aos princípios, às técnicas e às áreas funcionais do saber administrativo foram abordadas. Considera-se relevante especificar a discussão da gestão em cada uma dessas dimensões de análise, por compreender-se que pensar a gestão para além de um paradigma funcionalista envolve analisar as visões de mundo (ontológicas e epistemológicas) que interferem na elaboração dos princípios e técnicas gerenciais (Tragtenberg, 1971, Burrell\& Morgan, 1979; Faria, 2009).
Enquanto resultados, observou-se que a dimensão das técnicas/áreas funcionais em todos os canais de publicação foi o eixo de maior abordagem, variando de $47,2 \%$ a $51,9 \%$ nos trabalhos que trataram desse tema. Em seguida, observou-se a ênfase nos princípios que deveriam reger uma gestão na Economia Solidária, representando entre $38,9 \%$ a $44,4 \%$ dos trabalhos. Com números menos expressivos, constataram-se trabalhos que se destinaram a tratar de mudanças sob o ponto de vista ontológico e epistemológico do saber administrativo (Tabela 5).

Tabela 5

Ênfase das contribuições da gestão nos congressos e periódicos nacionais

\begin{tabular}{|c|c|c|c|c|c|c|c|c|}
\hline $\begin{array}{l}\text { Qual a ênfase nas } \\
\text { contribuições } \\
\text { obtidas? }\end{array}$ & $\begin{array}{c}\text { Congressos } \\
\text { nacionais }\end{array}$ & $\%$ & $\begin{array}{l}\text { Periódicos } \\
\text { nacionais }\end{array}$ & $\%$ & $\begin{array}{l}\text { Dissertações-teses } \\
\text { nacionais }\end{array}$ & $\%$ & $\begin{array}{l}\text { Literatura } \\
\text { internacional }\end{array}$ & $\%$ \\
\hline $\begin{array}{l}\text { Técnicas/ áreas } \\
\text { funcionais }\end{array}$ & 17 & 47,2 & 13 & 48,2 & 10 & 47,5 & 14 & 51,9 \\
\hline Princípios & 14 & 38,9 & 12 & 44,4 & 9 & 42,9 & 11 & 40,7 \\
\hline Ontologia & 1 & 2,8 & 2 & 7,4 & 1 & 4,8 & 2 & 7,4 \\
\hline Epistemologia & 4 & 11,1 & 0 & 0 & 1 & 4,8 & 0 & 0 \\
\hline TOTAL & 36 & 100 & 27 & 100 & 21 & & 27 & 100 \\
\hline
\end{tabular}

Fonte: criada pelo autor

Feitas as considerações gerais sobre a produção da gestão na Economia Solidária, e com o intuito de ilustrar contribuições presentes na revisão da literatura que possam servir de referências para o tema, buscou-se enumerar alguns trabalhos que ressignificam a gestão na Economia Solidária, desde o ponto de vista ontológico até as questões vinculadas às técnicas e áreas funcionais do saber administrativo.

Delas, no que se refere ao ponto de vista ontológico, é interessante citar os trabalhos de Silva Junior (2005), Vecchio, (2006) e Meira (2009), que discutem a complexidade organizacional em que está inserida a Economia Solidária, compreendendo e ressaltando a constante tensão com o sistema, baseada na aceitação dialética dos conflitos como inerentes a espécie humana. Isso implica pensar a gestão na Economia Solidária não como um purismo gerencial ou em uma única racionalidade (as quais muitos autores vêm categorizar como substantiva), mas compreender que discutir a gestão na Economia Solidária é adotar a relação conflituosa e não harmônica em que se baseiam as suas organizações.

No mesmo sentido, ao negar ideias de um pressuposto ontológico apenas objetivista, autores como Kliksberg (1999), Klechenet al., (2008), Gottig (2010), Roa e Hur (2010) trazem para 
a discussão as dimensões subjetivas na gestão, o que envolve tratar da autoestima dos sujeitos envolvidos, da ideia de que os resultados e do próprio êxito não se limitam ao lucro e dasvariáveis subjetivas como questões que interferem na eficiência das organizações.

Tais ampliações das dimensões ontológicas (saindo de um paradigma extremamente objetivista para considerar a intersubjetividade da gestão) contribuem também para ampliar as dimensões de análise, conforme mostram Reis (2005), Guzman (2009), e Dias (2011). Os autores abordam a necessidade de se considerar na gestão dos empreendimentos solidários não só as dimensões mercantis provenientes das receitas das vendas de produtos e serviços, mas as questões não mercantis e não monetárias, como: subsídios de governos, doações, trabalho militante, práticas reciprocitárias que fazem parte da sustentabilidade das organizações solidárias.

No que se refere a questões epistemológicas, autores como Misoczkyet al. (2004), Klechenet al. (2008) e Meira (2009) abordam a importância de se relativizar o modo de gestão na Economia Solidária, não mais pensando em modelos a serem replicados, visto que se contrariam ideias básicas de autonomia e independência, mas sim em conceitos e princípios deliberados por cada coletivo de acordo com suas necessidades.

No mesmo sentido de contrapor a lógica epistemológica positivista, autores como Vizeu (2003) e Nascimento (2009) contribuem ao desconstruir a ideia de que só é importante e só se faz gestão se há a racionalização e a formalidade dos processos gerenciais. Conforme sustentam os autores, nas organizações solidárias as relações interpessoais se baseiam antes na reciprocidade e no sentimento de solidariedade subjacente aos valores que predominam no contexto. Dessa forma, a informalidade corresponde a uma importante característica das organizações solidárias, por ser o mecanismo de comunicação informal mais próximo dos imperativos do reconhecimento intersubjetivo obtido pela linguagem, o que significa considerar a gestão não apenas como uma prática formal.

No que se refere aos princípios que sustentariam a gestão na Economia Solidária, ainda que não proponham a criação de leis gerais, mas sim algumas reflexões que podem ser utilizadas e deliberadas por cada coletivo, observam-se estudos que visam trazer contribuições para a área, como os trabalhos de Dornelles e Delagnello (2003), Martinez (2005), Vargas de Faria (2006), Toledo (2008), e Misoczkyet al. (2008).

Desse modo, se nas teorias da gestão tradicional os princípios que sustentam o modo de organização do trabalho se baseiam nas ideias da aceitação da hierarquia, da meritocracia e da divisão do trabalho, nas organizações coletivistas as propostas de se pensar a gestão passam pela necessidade de reestruturação do poder e de sua estrutura organizacional. Observa-se, assim, que a maioria dos autores considera como princípios da gestão coletiva a distribuição equitativa do capital e das rendas, a negação das hierarquias e a implementação de modos de organização do trabalho que conciliam o pensar com o agir (Christoffoli, 2000; Costa \& Frasson, 2005; Toledo, 2008; Baptista, 2011).

No mesmo sentido, observa-se também uma ênfase em considerar a autoridade, a responsabilidade e o controle como um pressuposto do coletivo e a importância da participação e da circulação das informações serem coletivas e abertas a todos nos diversos níveis institucionais das organizações (Costa \&Frasson, 2005; Vargas de Faria, 2006; Baptista, 2011).

Quanto às técnicas administrativas, observaram-se contribuições nos trabalhos de Misoczkyet al. (2008) e Meira (2009) ao ressaltar-se como um meio de se combater a formação de hierarquia é o fortalecimento do papel das assembleias ou qualquer outra forma de manifestação coletiva na qual se enfatizem enquanto instância máxima de decisão os interesses do coletivo. Em similaridade, Chiariello e Eid (2013) sustentam a importância da constituição de papéis holísticos para os quais os membros possuam um conhecimento politécnico. Os autores complementam realizando a diferença entre o conceito de trabalho polivalente (presente nos modos flexíveis de gestão) e a ideia de politecnia adequada aos empreendimentos solidários. Enquanto a polivalência apenas tangencia a unificação entre gestão e execução, sem contudo questionar a propriedade privada dos meios de produção, por outro lado, a politecnia apresenta a possibilidade de fusão entre as esferas de gestão e execução do trabalho, tendo como horizonte a autogestão dos empreendimentos pelos trabalhadores.

Outra possibilidade que caminha no sentido da politecnia consiste na rotatividade de funções, principalmente com o intuito de evitar a concentração do poder via conhecimento técnico (Rothschild, 1979; Pedrini, 2000). Ao analisar o método de rotatividade em uma empresa recuperada pelos trabalhadores, Pedrini (2000) constatou significativas vantagens em comparação às organizações tradicionais, sendo inclusive vista como uma estratégia para superar a hierarquia entre o trabalho intelectual e manual e alcançar maior conhecimento dos envolvidos.

Ressaltam-se ainda contribuições referentes aos modos de repensar a organização do trabalho nos estudos de Christoffoli (2000). Ao analisar uma cooperativa agrícola, o autor verificou que seus membros utilizaram comissões para distribuir as funções, o que serviu para facilitar a união do pensar e do agir e a circulação de informações e conhecimentos, bem como as tomadas de decisões coletivas.

Por fim, considera-se relevante também apontar estudos que discutiram a readequação das tradicionais áreas funcionais do saber administrativo (finanças, contabilidade, marketing, produção) para as organizações solidárias. Apesar de se compreender que a essência da divisão dessas áreas tem o cerne na acentuada divisão do trabalho (Motta, 1981; Alvesson \& Willmott, 1992), a proposição de ideias que buscam repensar as temáticas pode servir de base para auxiliar nas práticas administrativas nas organizações solidárias.

Dentre os principais estudos, citam-se os esforços de repensar as finanças e contabilidade para a área, apontando que, se 
historicamente esse conjunto de funções tem por pressuposto a medição, o controle e aferição dos lucros das organizações, para as organizações solidárias seria relevante relativizar inclusive o nível de rentabilidade que se espera. Sendo assim, autores como Rutkowvski (2008) e Neves (2009) apontam que a rentabilidade na Economia Solidária deve considerar o equilíbrio dos interesses não só dos associados, mas também dos demais atores envolvidos, como consumidores, apoiadores e a comunidade em geral. Isso implica repensar a rentabilidade para além dos interesses econômicos da organização.

Gaiger (2009) e Filho (2011) ressaltam ainda a necessidade de ressignificar inclusive os indicadores das organizações solidárias, considerando que indicadores de avaliação e lucratividade devem envolver não apenas os aspectos econômicos, mas também os retornos sociais que a organização estimula, como melhorias na qualidade de vida, aumento do capital social, processos formativos e democráticos.

No campo da contabilidade, observam-se trabalhos como os de Westerdahl (2001) e Santos (2008), que mostram a necessidade de se pensar uma contabilidade social para o contexto solidário. Dentre as sugestões, ressaltam que é necessário o emprego de uma contabilidade que não se limite apenas a registrar dados numéricos e econômicos, mas também os retornos provenientes do aumento da qualidade de vida dos envolvidos e os benefícios gerados para a sociedade. Outra contribuição envolve os estudos de Almeida(2006), que enfatizam a importância das modificações dos termos técnicos utilizados tradicionalmente para uma linguagem e métodos mais acessíveis à realidade da Economia Solidária. Além disso, enfatiza que é necessário repensar os meios de divulgação de informações contábeis, como formulários, modelos específicos e relatórios condizentes com essa realidade, além de criar mecanismos próprios que abordem a questão da contabilidade por fundos, a contabilidade orçamentária e a mensuração do resultado econômico.

No que se refere à discussão do marketing nas organizações solidárias, ainda que historicamente o conceito e suas técnicas estejam atreladas aos interesses das grandes corporações (Morgan, 1992), bem como sua própria etimologia já faça referência às relações diretas com o mercado, transmitindo um histórico estritamente econômico (Cançado et al., 2010), autores como Betanho e Eid (2007) e Pacagnanet al. (2012), trazem contribuições ao recorrer ao termo marketing social. Nesse sentido, os autores definem que na Economia Solidária não se deve centrar o marketing apenas nos objetivos econômicos e nas vendas, mas nas inter-relações de benefício mútuo com clientes, fornecedores, parceiros e organizações, sem haver exploração em nenhuma dessas relações, como um incentivador de mudanças de valores e comportamentos dos sujeitos.

Além dessas questões, Oliveira (2006) e Cançado et al. (2010) afirmam a necessidade de se repensarem algumas dimensões técnicas, vinculadas, por exemplo, às questões do mix marketing (entendido por produto, preço, praça e promoção). Ressaltam que, se nas organizações solidárias a lógica do consumo solidário se posiciona como central, o marketing pode servir, nesse caso, como um meio para incentivar os clientes a dar preferência às organizações solidárias.

Quanto às discussões da administração da produção, Rutkowski (2008), Salm e Menegasso (2010) e Lourenço (2012) trazem contribuições para o tema ao apontar que, no contexto das organizações solidárias, não parece apropriado empregar simplesmente a economia dos movimentos, que é o método usado para a racionalização do trabalho. Propondo ressignificar os processos de produção, os autores ressaltam que a produtividade deve depender do saber, da motivação e do controle de cada associado. Desse modo, a regulação das atividades das organizações solidárias, o ritmo adequado de trabalho nem sempre deve ser aquele que permite produzir mais em menos tempo, mas em produzir o suficiente para todos, considerando as diferenças de capacidade de cada um.

Por fim, vinculando-seà questão produtiva, constataram-se tentativas de repensar as questões do próprio layout organizacional. Conforme observa Parra (2002), uma das formas simbólicas de representação da dominação social e política ocorre por meio da divisão do trabalho, manifestando-se na própria separação do espaço físico entre o setor de produção e administrativo. Em contraproposta, nas experiências autogestionárias relatadas por Coelho (2007), observa-se que uma das primeiras mudanças em uma fábrica recuperada ocorreu no espaço físico do trabalho. Antes, as máquinas eram distantes umas das outras e deixavam os trabalhadores de costas um para o outro, o que reduzia as relações pessoais. Nesse sentido, foram feitas mudanças nas posições dos trabalhadores e das máquinas, o que facilitou as conversas e tornou o ambiente mais sociável, ainda que isso tenha reduzido um pouco o ritmo de trabalho. Azevedo (2007) também apresenta um exemplo semelhante em uma das cooperativas filiadas a Mondragon. Ao reestruturar a organização das atividades, a cooperativa em questão modificou o espaço físico da planta, criando células de trabalho, o que aumentou a comunicação e a integração entre os participantes.

\section{Considerações finais}

Com o intuito de trazer aportes para a discussão da gestão na Economia Solidária, o trabalho propôs realizar um balanço sobre a produção da gestão na Economia Solidária. Buscou-se por meio do uso da investigação das dissertações e teses, dos periódicos nacionais e internacionais e dos congressos na área de Administração apresentar a produção da temática, problematizando seus limites e desafios, bem como ilustrar trabalhos que trouxeram inovações para a discussão da gestão naEconomia Solidária.

Enquanto tendência, constatou-se a concentração da produção principalmente nas dissertações e teses nacionais, seguidos pelos congressos nacionais, dissertações e teses internacionais e, em menor número, nos periódicos nacionais. Tais 
resultados implicam o seguinte questionamento, para o qual este trabalho não pôde trazer inferências: o menor número de publicação em periódicos nacionais é reflexo da dificuldade de aceitação dos trabalhos ou de um baixo número de submissões?

Ressalta-se ainda que a presença de trabalhos nos periódicos internacionais, principalmente dos níveis mais elevados de avaliação, foi praticamente nula, indicando que o tema não ocupa espaço nos periódicos mais avaliados da área. Da mesma forma, ao se investigar a natureza dos trabalhos, observou-se que a grande maioria dos trabalhos de origem nacional recorreu a estudos de natureza teórica, com poucas investigações empíricas que discutiam contribuições. Considera-se enquanto reflexão que a restrição de casos empíricosix que tragam aportes para a gestão nas organizações solidárias incorre no risco de não se inovar sobre o tema, reproduzindo os mesmos conceitos teóricos.

Observou-se também que, referente às unidades de análise nas quais os trabalhos se basearam para discutir a gestão, há uma predominância da abordagem relacionada aos empreendimentos solidários de pequeno porte, refletindo uma leitura empírica da realidade brasileira com base nos recentes mapeamentos da Senaes (2014). Porém, a discussão da gestão de redes solidárias e cadeias produtivas ainda se mostrou muito baixa na área, principalmente ao se considerar a necessidade de suporte para atuais políticas nacionais de Economia Solidária baseadas no incentivo da sustentabilidade por essas vias. No mesmo sentido, outra limitação se refere ao acentuado número de trabalhos que não estabeleciam a unidade de análise a que destinavam o tratamento da gestão, o que parece uma restrição metodológica, haja vista que a simples denominação comum pode esconder uma grande diversidade de práticas que merecem ser consideradas no caso da gestão.

Em contraponto, um aspecto positivo da tendência da produção da gestão na área é a negação da lógica epistemológica funcionalista, pois a grande maioria dos autores brasileiros e internacionais deram indícios de compreender a concepção da gestão como uma construção política.A importância desse posicionamento é fundamental para a construção de instrumentais de gestão na Economia Solidária a partir do momento em que se nega a impossibilidade de replicação absoluta sem se considerar a necessidade de ressignificações. Nesse sentido, foi possível ilustrar contribuições de trabalhos que trouxeram inovações, sejam na ressignificação das bases ontológicas, epistemológicas e seus princípios, até na proposição de técnicas do saber administrativo para as organizações solidárias.

Feitas as considerações gerais, enquanto limitações deve-se ressaltar que, ao fazer a pré-seleçãodos trabalhos com base nas palavras-chaves, talvez alguns trabalhos que abordassem a economia solidária, mas não fizessem menções nessa etapa, não tenham sidoselecionados. Da mesma forma, apesar do esforço de se mapear a produção da área, o trabalho não buscou esgotar a temática, mas apenas se situar como um esforço inicial, compreendendo que o campo da Economia Solidária figura ainda como um desafio intelectual, que impõe ao pesquisador a necessidade de desconstruir e reconstruir o referencial teórico utilizado para tentar aportar inteligibilidade a este campo. Da mesma forma, a necessidade de construção de um referencial analítico apropriado para o estudo da Economia Solidáriadentrodo campo da Administração exige, consequentemente, o alargamento desse campo, de modo a incorporar novas noções capazes de captar, explicar e avaliar essa natureza de organização.

Nesse sentido e em conclusão, tem-se o reconhecimento da Economia Solidária como um fato organizacional empírico, o qual, ao mesmo tempo em que guarda similaridades e distanciamentos com outras formas já reconhecidas de organização, apresenta também singularidade que requer a construção de um referencial teórico específico, de caráter interdisciplinar e em permanente diálogo e negociação com as noções e conceitos já estabelecidos no campo da Administração (Costa \& Carrion, 2011).

\section{Referências bibliográficas}

Almeida, E. (2006). Contabilidade e autogestão: um estudo sobre a dimensão contábil nos processos de autogestão dos empreendimentos de Economia Solidária. Dissertação (Mestrado em Contabilidade) - USP.

Alvesson, M; Willmott, H. (1992). Critical Management Studies. London: Sage.

Andion, C. (1998). Gestão em organizações da Economia Solidária: contornos de um problemática. Revista de Administração Pública, v.32, n.1, p.70-84.

Andion, C. (2005). A Gestão no Campo da Economia Solidária: Particularidades e Desafios, RAC - Revista de Administração Contemporânea, v. 9, n. 1, p.79-101, Jan./Mar.

Azevedo, A. (2007). Autogestão e Competitividade: Estudos de caso em cooperativas industriais brasileiras e bascas/espanholas. Tese (Doutorado em Geociências) - Unicamp.

Baptista, F. C. (2011).Percepctions of grassroots urban youth entrepreneurs about collective engagement: an extensive case study in East Africa. Dissertação. (Mestrado em Sociologia) - University of Amsterdam.

Betanho, C; Eid, F.(2007). Marketing para produtos da reforma agrária - O arroz agroecológico de Lagoa do Junco (RS). Gestão da Produção, Operações e Sistemas, v. 2, p. 77-87.

Burrell, G.; Morgan, G. (1979). Sociological paradigms and organization analysis. London: Heinemann Educational Books.

Calbino, D; De Paula, A, P. (2013). Economia Solidária: uma investigação sobre o estado da arte. Gestão Contemporânea, n. 14, 2013.

Calbino D, P; Paes de Paula, A P. (2014). A Mitologia da Ineficiência nas Organizações Solidárias: Em Busca da Ressignificação de um Conceito. Desenvolvimento em Questão, v. 12, n. 27, p. 42-65.

Cançado, A, C; Procópio, M, L; Pereira, J. (2010). Marketing Social: Origens, Desenvolvimento e Perspectivas. In: IV ENAPGS, Anais... Lavras, 2010.

Chiariello, C.L; Eid, F. (2013). A politecnia na dinâmica de gestão e execução do trabalho associado em cooperativas populares do MST. Revista ORG \& DEMO, Marília, v. 14, n. 1, p. 49-70, Jan./Jun.

Christoffoli, P, I. (2000). O desenvolvimento de cooperativas de produção coletiva de trabalhadores rurais no capitalismo: limites e possibilidades. Dissertação. (Mestrado em Administração) - UFPR.

Coelho, D. (2007). De catadores de rua a recicladores cooperados: Um estudo de caso sobre a formação e a gestão de uma cooperativa de reciclagem. Dissertação (Mestrado em Administração) - Mackenzie.

Costa, A; Frasson, G. (2005). Autogestão: Um novo/velho modelo em administração. Gestão e Regionalidade, v.1, n.65, p.16-47,jul/dez.

Costa, P, A. (2003). Um diagnóstico da gestão praticada em iniciativas de Economia Solidária e os seus desafios gerenciais: estudo de caso do município de Cachoeirinha. Dissertação. (Mestrado em Administração) Universidade Federal do Rio Grande do Sul.

Costa, P, A; Carrion, R. (2011). Situando a Economia Solidária no campo dos Estudos Organizacionais. Otra Economia, V.3, n.4, p.66-81.

Dalmoro, $M$, et al. (2007). Dominância epistemológica em estudos do campo: são ainda os administradores positivistas. XXXI ENANPAD, Anais...Rio de Janeiro.

Dias, T. (2011). A gestão social na região de Potiguar. Tese. (Doutorado em Administração) - Universidade Federal do Rio Grande do Norte.

Dornelles, S, B; Dellagnelo, E, H. (2003). Autogestão e Racionalidade Substantiva: a Bruscor - Ind. e Comércio de Cordas e Cadarços Ltda. - em Análise. In: XXVII ENANPAD, Anais..., Atibaia. 
Faria, J, H. (2009). Gestão Participativa: Relações de poder e de trabalho nas organizações. São Paulo: Atlas.

Fayol, H. (1980). Administração Industrial e Geral. São Paulo: Atlas.

Filho, P, R. (2011). As especificidades do processo de avaliação das organizações economia social. Revista Alcance, v.18, n.1, p.65-74, out./dez. França Filho, G. (2008). A via sustentável solidária no desenvolvimento local. O\&S, v.15, n.45, p.140-154, Abr./Jun.

Gaiger, L, I. (2009). Eficiência. In: CATTANI, A.D.(org.). Dicionário internacional da outra economia, p.169-175.

Gottig, A. (2010). ¿Qué se entiende por "éxito" en los emprendimientos productivos sociales? Tesis de Maestria, Universidad Nacional Gral. Sarmiento, Los Polvorines.

Guerreiro, J, et al. (2004). incubadora universitária tecnológica de cooperativas populares: uma proposta de política pública de crédito produtivo. XIV Seminário Nacional de Parques Tecnológicos e incubadoras de Empresas. Anais... Recife.

Guzman, I, P, R. (2009). Sustentabilidade em organizações econômicas camponesas (OECAS) das terras altas da Bolívia: um estudo de casos múltiplos. Dissertação (Mestrado em Administração) - Universidade Federal da Bahia.

Klechen, c, F; Barreto, R, O; Paes de Paula, A, P. (2008). Pilares para a compreensão da autogestão: o caso de um programa de habitação da prefeitura de Belo Horizonte. In: III ENAPG, Anais... Salvador.

Kliksberg, B. (1999). El rol del capital social y de la cultura em El proceso de desarrollo. In: Revista venezolana de gerencia, v.4, n.9, p.11-50.

Kotler, P; Armstrong, G. (2012). Princípios de Marketing. Prentice Hall.

Laville, J, L. (2003). Économie solidaire et démocratie. Hermes: Paris.

Lourenço, M, L. (2012). Subjetividade e cooperativismo: no contexto de uma cooperativa pautada nos princípios da Economia Solidária. Revista Cesumar, v.17, n.1, p.65-76, out./dez.

Magalhães, O, et al. (2004). Especificidades da gestão em de Empreendimentos na Economia Solidária - Breve estado da arte sobre o Tema. In: III Encontro Latino-Americano de Pesquisadores da Aliança Cooperativa Internacional. Anais... São Leopoldo.

Martinez, J, C. (2005). Como seguir compartiendo soluciones? La gestiondel ciclo de vida cooperativo. Cayapa, v. 5, n.9.

Meira, F, B. (2009). As encruzilhadas da autogestão: Imaginário e simbólico nas empresas assumidas por trabalhadores - uma análise em empreendimentos da Economia Solidária. Tese (Doutorado em Administração) - Fundação Getúlio Vargas-SP.

Misoczky, M, C; Silva, J; Flores, R. (2008). Autogestão e práticas organizacionais horizontalizadas: amplificando sinais. In: VEnEO, Anais.. Belo Horizonte.

Motta, F, C. (1981). Burocracia e Autogestão. A proposta de Proudhon. São Paulo: Brasiliense.

Moura, M; Meira, L. (2002). Desafios da Gestão em Empreendimentos Solidários. Bahia Análise e Dados, v.12, n. 1, p.112-132, jun./ago.

Nascimento, A. (2009). Escolhas e decisões em organizações da Economia Solidária: a participação como educatividade para a gestão social. In: II EnGPR, Anais... Curitiba.

Neves, E. (2009). A capacitação para a gestão de empreendimentos econômicos de Economia Solidária: experiências e propostas. Campinas, 2009. Dissertação (Mestrado em geociências) - UNICAMP.

Oliveira, L, C. (2006). Marketing social, comunicação e participação. Avanços e retrocessos na tentativa de planejar a comunicação de uma ONG de forma participativa. Rio de Janeiro, 2006. Dissertação (Mestrado em Administração) - FGV.

Pacagnan; M, N; Martos, S, R; De Moura, F, A. (2012). Contribuições e possibilidades práticas do marketing social para o campo da Economia Solidária: uma proposta preliminar. In: XV SIMPOI. Anais... São Paulo.

\footnotetext{
Apesar do número expressivo de publicações desse tema na área de Administração, há também uma ampla discussão no campo das Ciências Sociais.

ii A escolha desses trabalhos a partir de 1987 se justifica, pois essa data marca a disponibilidade das primeiras dissertações e teses no banco de dados da Capes.

iii'Devido aos diferentes anos de marco inicial dos periódicos, utilizou-se enquanto escopo uma revisão a partir de 1970, que marca o início dos periódicos mais antigos no campo da Administração, ainda que a etimologia Economia Solidária não fosse cunhada nesse período.

${ }^{i v}$ A escolha do marco inicial para identificação dos trabalhos marcada a partir de 1980 se justifica, pois foi o marco inicial dos primeiros congressos da área de Administração no Brasil.

vEnquanto critério para identificação dos trabalhos sobre a gestão na Economia Solidária, recorreu-se aos estudos que perpassavam pelo menos umas das dimensões ontológicas ou epistemológicas, princípios, técnicas
} ou áreas funcionais do saber administrativo.
Paes de Paula, A, P; Maranhão, C, M; Barros, A, N. (2009). Pluralismo, pósestruturalismo e gerencialismo engajado: os limites do movimento critical management studies. Cadernos Ebape. BR, v. 7, n. 3, p. 393-404.

Paes de Paula, A. P.; klechen, C. (2007) F. A Tradição Autônoma dos Estudos Críticos em Administração no Brasil: Um Estudo da Produção Científica de 1980 a 2004. In: XXXI ENANPAD. Anais... Rio de Janeiro.

Parra, H. (2002). Liberdade e Necessidade: Empresas de Trabalhadores Autogeridos e a Construção Sócio-política da Economia. Dissertação. (Mestrado em Filosofia), USP.

Pedrini, D, M. (2000). Bruscor: uma experiência que aponta caminhos. In: SINGER, SOUZA (orgs). A Economia Solidária no Brasil: a autogestão como resposta ao desemprego, p.31-48.

REIS, T. (2005). A sustentabilidade de empreendimentos de Economia Solidária - Pluralidade e Interconexão de dimensões. Dissertação (Mestrado em Administração) - Universidade Federal da Bahia, Salvador.

Roa, F, A; Hur, D. (2010). Grupos de geração de renda no Curso PréVestibular Psico-USP: uma experiência de autogestão em um cursinho popular. Cadernos de Psicologia Social do Trabalho, v.13, n.2.

ROTHSCHILD, W, J. (1979). The collectivist organization: an alternative to rational-bureaucratic models. American Sociological Review.Ohio: Ohio State University, v.44, n.4, p.509-527, jan./abr.

Rutkowski, J. (2008). Sustentabilidade de Empreendimentos econômicos: Umaabordagem na engenharia de Produção. Rio de Janeiro. Tese (Doutorado em Engenharia de Produção) - UFRJ.

Salm, J, F; Menegasso, M, E. (2010). A base epistemológica da ação administrativa nas organizações substantivas e a formação do gestor social. In: IV ENAPEGS. Anais... Lavras.

Santos, A. (2008). O contador-educador: contribuição para o desenvolvimento de empreendimentos solidários. Monografia. Curso de Especialização em metodologia de ensino, pesquisa e extensão em educação, UNEB.

Senaes - Secretaria Nacional de Economia Solidária. (2014). Boletim informativo, ano v, 2014. Acesso em 07 de jan. 2015. Disponível em http://portal.mte.gov.br/data/files/8A7C816A416FABB6014173C4E66C7839/ Acontece\%20SENAES\%202013\%20-\%20n34\%20ed\%20espercial.pdf.

Silva Junior, J. (2005). Fato Associativo e Economia Solidária: A experiência da ASMOCONP/Banco Palmas. Bahia. Dissertação (Mestrado em administração) - UFBA.

Singer, P. (2008). Economia Solidária: Entrevista. Revista Estudos Avançados, v.22, n.62, 2008.

Singer, P. (2002). Introdução a Economia Solidária. São Paulo: Fundação Perseu Abramo.

Toledo, D, A. (2008). Pensando categorias de análise para o exercício da prática da autogestão. In: XXXII Enanpad. Anais... São Paulo.

Tragtenberg, M. (1971). A teoria geral da administração é uma ideologia? Revista de Administração de Empresas, v.11, n. 4, p.7-21, out./dez.

Vargas de Faria, J, R. (2006). Organizações Coletivistas de Trabalho: referência para os empreendimentos populares solidários. In: IV ENEOS, Anais... Porto Alegre.

Vecchio, R, A. (2006). Conhecendo uma Experiência Autogestionária: Possíveis Contribuições aos Estudos Organizacionais. In: XXX Enanpad. Anais... Rio de Janeiro.

Vizeu, F. (2003). Algumas contribuições da teoria da ação comunicativa para a área de organizações. In: XXVII ENANPAD, Anais...Atibaia.

Westerdahl, S. (2001). Prácticas contables en cooperativas rurales. CIRIECEspaña, Revista de Economía Pública, Social y Cooperativa, n. 39, p.149168, Nov.

viObservou-se nas publicações que, apesar de os autores estarem vinculados a centros de pesquisa anglo-saxões, suas nacionalidades eram latinas.

viiEnquanto recorte metodológico, partiu-se do pressuposto que foram nos trabalhos que negavam a neutralidade da gestão que se encontram evidências para uma ressignificação da gestão. Para tal, foram analisados os 111 trabalhos que consideravam a gestão como ideológica.

viii Utilizou-se dos conceitos de Burrell e Morgan (1979) para se tratar da ontologia e da epistemologia nas organizações. Por ontologia entende-se o plano da ciência que trata da essência do fenômeno sob investigação, e, epistemologia, as bases do conhecimento, ou seja, a maneira como alguém pode entender o mundo e transmitir esse conhecimento para seus semelhantes em forma de comunicação.

O trabalho não teve a pretensão de discutir quais os fatores levaram ao baixo número de trabalhos empíricos no cenário nacional. No entanto, as hipóteses podem tangenciar pelo reduzido número de produção dessa natureza ou mesmo pela dificuldade de aceitação de publicações em congressos e periódicos. 